\title{
Interprofessional Education Competition During the COVID-19 Pandemic at King Saud University: Benefits and Challenges
}

This article was published in the following Dove Press journal: Journal of Multidisciplinary Healthcare

\begin{abstract}
Afnan Alrasheed ${ }^{1} * *$
Noura Altulahi ${ }^{1} *$

Mohamad-Hani Temsah (D) ${ }^{2,3}$

Zakaria Almasri ${ }^{4}$

Sultan Alghadeer ${ }^{\prime}$

Abdullah M Mubarak $\mathbb{D D}^{5}$

Hana Alzamil (1D ${ }^{6}$

Adel S Bashatah $\mathbb{1 D}^{7}$

Yousif Asiri'

Yazed AIRuthia (D) ${ }^{1,8}$

'Department of Clinical Pharmacy,

College of Pharmacy, King Saud

University, Riyadh, Saudi Arabia;

${ }^{2}$ Department of Pediatrics, College of

Medicine, King Saud University, Riyadh,

Saudi Arabia; ${ }^{3}$ Department of Pediatrics,

King Saud University Medical City, King

Saud University, Riyadh, Saudi Arabia;

${ }^{4}$ Department of Nursing, King Saud University Medical City, Riyadh, Saudi Arabia; ${ }^{5}$ Department of Basic Science, Prince Sultan Bin Abdulaziz College for Emergency Medical Services, King Saud University, Riyadh, Kingdom of Saudi Arabia; ${ }^{6}$ Physiology Department, College of Medicine, King Saud University, Riyadh, Saudi Arabia; ${ }^{7}$ Department of Nursing Education and Administration, College of Nursing, King Saud University, Riyadh, Saudi Arabia; ${ }^{8}$ Pharmacoeconomics Research Unit, College of Pharmacy, King Saud University, Riyadh, Saudi Arabia

*These authors contributed equally to this work
\end{abstract}

Correspondence: Yazed AIRuthia College of Pharmacy, King Saud

University, P.O. Box 2454, Riyadh, II45I, Saudi Arabia

Tel +966 I | 4677483

Fax +966 II 4677480

Email yazeed@ksu.edu.sa
Background: The objective of this qualitative study was to explore the value of virtual IPE competition that involved a COVID-19 case among healthcare students and the lessons that can be learned to improve this experience in the future.

Methods: The 27 senior students from the colleges of medicine, pharmacy, nursing, and paramedics were invited to two focus groups that followed the IPE competition and lasted 60 minutes each. A semi-structured focus group discussion guide was used in the focus group discussion to explore the benefits and limitations of the virtual IPE experience. Verbatim transcription of the two video-recorded sessions was conducted, and inductive thematic analysis was performed to uncover different emerging themes.

Results: The number of students who consented to participate was 16 (59.26\%). The IPE virtual competition was perceived favorably by all students; however, multiple organization and communication barriers were reported. Although the participants liked the IPE virtual competition, they clearly stated their preference for an in-person IPE competition over the virtual one. Managing a COVID-19 case was not perceived favorably by some participants due to the absence of evidence-based clinical guidelines supporting certain treatment protocols over others. Thus, some participants preferred a non-COVID-19 case where clear and evidence-based guidelines exist.

Conclusion: The use of different IPE strategies to enhance healthcare students' collaboration and understanding of their roles in the multidisciplinary healthcare team, especially during pandemic times, such as COVID-19, is possible. Future studies should examine new and innovative IPE strategies that address the identified limitations of virtual IPE.

Keywords: interprofessional education, collaboration, COVID-19, healthcare, Saudi Arabia

\section{Introduction}

The success of any healthcare system depends mostly on the quality of the healthcare personnel that runs that system. With the rapid advances in healthcare delivery, the healthcare team became more diverse, with each team member performing a unique yet complementary role in the healthcare provision. However, certain quality attributes and skills, such as effective communication, coordination between the team members, and leadership, have to be acquired by each healthcare team member to complement each other's roles and improve the quality of healthcare. ${ }^{1}$ Therefore, the new generation of healthcare providers need to be equipped with these essential skills before joining the healthcare workforce. ${ }^{2}$ Interprofessional education (IPE) for the undergraduate healthcare students through 
the use of simulation-based learning and case scenarios has shown to be effective in enhancing communication between the various healthcare team members. ${ }^{3-5}$

The improvement in the interprofessional communication between the healthcare team members from different specialties was the main reason behind the institute of medicine (IOM, 1972) support for incorporating IPE in different healthcare programs' curricula. ${ }^{6}$ Therefore, the American Association of Colleges of Nursing, the American Association of Colleges of Pharmacy, and the Liaison Committee on Medical Education have included different IPE elements in their accreditation standards for nursing, pharmacy, and medical colleges, respectively. ${ }^{7}$ Moreover, establishing IPE frameworks in the healthcare curricula has shown a positive impact on the patient quality of care since they define the expected roles and responsibilities guided by a defined set of professional and ethical values for each healthcare team member. ${ }^{8}$

With the rapidly evolving COVID-19 pandemic, especially in the early stages of the crisis, the education sector has been hit hard and struggled to keep the educational process going for students at all levels of study. ${ }^{9}$ Therefore, the virtual learning environment became the norm during this pandemic, and many programs that require practical training, especially in healthcare, adopted new teaching techniques, such as simulation-based learning in a virtual environment. ${ }^{10}$ However, multiple challenges hinder the success of the virtual educational models in ensuring the quality of education for students in general and healthcare students in particular. These challenges include effective classroom engagement, limited awareness of the technologies and softwares used in virtual education, ineffective communication between students and their teachers, balancing personal and work duties, and the cost of adopting specific medical simulation-based models for practical sessions. ${ }^{10-12}$ Therefore, different universities and educational institutions are trying to adapt to the new reality amid the COVID-19 pandemic to manage the numerous challenges and facilitate the learning process. ${ }^{13}$

Despite the numerous challenges faced by most healthcare educational institutions, adopting and implementing IPE cannot be stressed enough, given the importance of effective collaboration between different healthcare team members during this unconventional time. ${ }^{14}$ The adoption of IPE during the COVID-19 pandemic requires the employment of various teaching and learning approaches, such as synchronized teaching with breakup sessions, asynchronized discussion, and case-based assignments. These different approaches are time-consuming and effort- demanding during conventional times and requiring greater time and effort to coordinate IPE educational sessions during this unprecedented time. ${ }^{15}$ Additionally, designing a virtual IPE activity and evaluating the students remotely is another hurdle that must be addressed to achieve the desired learning outcomes. ${ }^{16}$

Although the virtual learning environment during the COVID-19 pandemic for healthcare students is fraught with multiple limitations, such as reduced student engagement and loss of assessments, ${ }^{17}$ the IPE virtual experience has shown to improve student engagement and interaction between one another and their mentors. ${ }^{14,15}$ In a recently published study that utilized a mixed-methods design to explore students perspective regarding the virtual IPE learning among students from various healthcare colleges and universities in the state of Oregon, United States, who participated in a virtual IPE experience before participating in the study, the IPE learning was perceived favorably by most participants. Moreover, most participants felt that the virtual IPE learning is not significantly different from the in-person courses in terms of achieving the objectives of IPE based on the World Health Organization (WHO) definition of IPE. Furthermore, the participants felt more connected to other students from different healthcare colleges in the virtual learning format in comparison to the in-person format. ${ }^{17}$ Therefore, the virtual IPE teaching environment might be the answer to address the limitations of the virtual learning environment encountered during the COVID-19 pandemic. $^{18,19}$

In Saudi Arabia, the IPE in healthcare education is largely absent despite the familiarity of IPE by many faculty members in various healthcare colleges, and the willingness of many to include IPE as an integral part of the undergraduate healthcare curricula as suggested by a recently published study. ${ }^{20}$ Therefore, a group of healthcare faculty members decided to explore the feasibility of implementing IPE during the COVID-19 pandemic by conducting a competition among students from various healthcare colleges to encourage them to participate and collaborate due to the lack of exposure to IPE for most students in the healthcare colleges in Saud Arabia.

\section{Methods}

\section{Context}

King Saud University is the oldest public university in Saudi Arabia. It includes six different healthcare colleges (eg, college of medicine, college of pharmacy, college of 
dentistry, college of applied medical sciences, college of nursing, and college of emergency medical services (paramedics)). The university offers different undergraduate and post-graduate healthcare programs using the traditional educational model. Although the IPE is encouraged and taught as a concept in some healthcare colleges, such as the college of medicine, it is not implemented as a course or part of a course in any college. ${ }^{21}$ Therefore, the deanship of skills development launched different initiatives to assess faculty members' willingness from various healthcare colleges to adopt and implement IPE. ${ }^{20}$ Moreover, the students' perspective regarding the use of IPE in teaching different clinical case scenarios was deemed instrumental in the success of any future IPE course. Thus, the university has recently launched an interprofessional competition between students from different healthcare colleges during the COVID-19 pandemic to explore the benefits and challenges of introducing a new virtual IPE course for healthcare students.

\section{Study Design and Setting}

Before the virtual focus group discussions that aimed to explore the value of a virtual IPE competition among a group of healthcare students, the deanship of skills development has invited 27 students from the colleges of medicine, pharmacy, nursing, and paramedics. The invitation came after an online announcement on the Twitter $^{\mathbb{R}}$ account of the university's deanship of skills development where interested students filled out an online form embedded in the announcement. Students were selected by a designated committee of faculty members representing these colleges. The selection criteria were based on the applicants' grade point average (GPA), willingness and commitment to participate in the IPE competition, and English proficiency since the competition was in English, which is the teaching language in all healthcare colleges, to ensure homogeneity between the competing teams. The two-day competition was named Interprofessional Education Collaboration and Competition (IPECC) and took place virtually on Zoom ${ }^{\circledR}$ with multiple breakout rooms. The 27 students (nine from the college of pharmacy, eight from the college of paramedics, six from the college of nursing, and six from the college of medicine) were randomly distributed into four IPE competing teams (eg, six to seven students in each team), where each college was represented by at least one student.

A pre-competition orientation consisting of five 30minute virtual lectures about the competition, and IPE concept and applications, especially during the COVID19 pandemic, were provided by five faculty members from the participating colleges (medicine, nursing, paramedics, and pharmacy). On the second day, students were asked to join their assigned IPE groups virtually before being split into four Zoom ${ }^{\circledR}$ breakout rooms. The students were then assigned a similar COVID-19 case, which was developed by the organizing committee that consisted of five healthcare faculty members, and were provided with all relevant laboratory values and imaging studies (eg, x-ray) (Appendix 1). At the end of the case, multiple-choice questions (MCQs) and short answer questions were presented. Students were given the answer sheet and were asked to work together to solve the questions and submit their answers online in 120 minutes (two hours).

Furthermore, the students were asked to keep the webcam open while discussing the case with their colleagues in each group. The whole 120 minutes discussion sessions were observed by two faculty members in each group and video-recorded to be graded by the organizing committee. Students IPE skills were assessed using the observational tool for simulation enhanced interprofessional education (sim-IPE), which is a tool originally developed to examine students' ability to work together in an interprofessional team, such as assigning roles, coming up with a care plan, and using TeamSTEPPS ${ }^{\circledR}$ communication tools (huddle, closed-loop communication). ${ }^{22}$ Approximately one-third of the grade was based on providing the right answers to the case questions, and two-thirds for the IPE skills as assessed by the sim-IPE. The winning groups (eg, first, second, and third) based on their scores received awards and gifts from the deanship of skills development.

\section{Data Analysis}

The students were invited to participate in interprofessional focus group discussions right after the competition. Those who accepted the invitation and consented to participate after being informed about the purpose of the study, their right to withdraw from the study at any time, and that their responses will be anonymized, were asked to enter two separate virtual breakout rooms. Each focus group discussion lasted about 40 minutes and was video-recorded. Verbal and non-verbal communication cues were observed and documented by the first two authors [AA and NA] during the focus group discussions, which were moderated by the senior author [YA]. A semi-structured focus group discussion guide was used to explore the students' experience with this virtual competition. The guide included 
questions on the students' perception of IPE in a virtual environment, learned lessons from the virtual IPE experience, the viewed opportunities that students think should be utilized to advance the IPE during the COVID-19 pandemic, and the perceived hindrances that limit the effective implementation of IPE during the COVID-19 pandemic in a virtual environment. The two focus group discussions were video recorded and transcribed verbatim by the first two authors [AA and NA]. Transcripts were subject to inductive thematic analysis, and key excerpts were extracted manually by the first, second, and last authors $\left[\mathrm{AA}, \mathrm{NA}\right.$, and YA]. ${ }^{23}$ Extracted themes were checked by the third and seventh authors [MHT and HA] who had good experience in qualitative research to assess the reliability of the findings before being reviewed by the rest of authors. The data were handled based on the ethical principles of the Helsinki's declaration and all responses were anonymized. ${ }^{24}$ The focus group discussions were held in June 2020, and the study was approved by the institutional review board of the College of Medicine at King Saud University (Project No. E-19- 4314).

\section{Results}

Out of the 27 students who participated in the IPEC, 16 (59.26\%) consented to participate in the focus group discussions (eg, eight students in each focus group discussion) (Table 1). The qualitative data analysis revealed five themes as follows:

\section{The Interprofessional Competition (IPEC) Facilitated Communication Between Students from Various Healthcare Colleges}

The students liked the competition, which represented the first IPE experience for most of them, and enabled them to collaborate with students from other healthcare colleges:

"Actually, this is my first time working or dealing with students from other health care colleges. This will help me a lot before starting my internship at the hospital." (Female student, College of Medicine).

"I got the chance to interact with nursing and paramedic students, it's my first time!" (Female student, College of Pharmacy).

"I had no IPE experience before, the competition was amazing! I worked with students from other colleges for the first time!" (Male student, College of Emergency of Medical Services).
Table I Participant's Baseline Characteristics $(n=16)$

\begin{tabular}{|l|c|}
\hline Characteristics & $\mathbf{n}(\%)$ \\
\hline College & $3(18.75)$ \\
\hline Medicine & $6(37.5)$ \\
\hline Pharmacy & $\mathrm{I}(6.25)$ \\
\hline Nursing & $6(37.5)$ \\
\hline Paramedics & \\
\hline Gender & $6(37.5)$ \\
\hline Male & $10(62.5)$ \\
\hline Female & \\
\hline
\end{tabular}

"The experience was great; everyone had a chance to know more about other health professionals' roles, where we can benefit from each other and know how the teamwork should be and who should do this and that." (Male student, College of Pharmacy).

\section{The Interprofessional Competition} (IPEC) Improved Students' Awareness of

\section{Their Roles}

The students reported that this competition was a new learning environment that they have not been exposed to before. Furthermore, some have reported that this new learning environment improved their understanding and ability to manage clinical cases:

"Today, I learned that to manage a clinical case, I have to work with a team from different specialties and with different perspectives, values, and roles." (Female student, College of Pharmacy).

"It was a useful and beneficial way of learning (raised his eyebrows); it helped me to define the roles of other professions." (Male student, College of Emergency of Medical Services).

\section{The IPE Competition Helped Students Identify Their Weaknesses and Strengths and Highlighted the Importance of Teamwork}

This activity enabled students to identify their own strengths and weaknesses with regard to the scope of their knowledge and role boundaries: 
"It was a great experience because I got to know the limits of my knowledge, and how we complement each other" (Female student, College of Medicine).

"It was really different than what I was expecting from this activity; I learned from my colleagues more than providing." (Male student, College of Emergency of Medical Services).

\section{The Virtual Learning Platform is Useful but Not Perfect}

The students' overall perception of the virtual IPE platform was favorable; however, some have voiced their preference for in-person IPE competition:

"I learned from my colleagues, the communication was alright, and we had fun. I was expecting something worse, but thankfully it went fine" (Female student, College of Pharmacy).

"I think it was a very successful experience even though it was virtual." (Female student, College of Medicine).

"If we can repeat this activity again in-person, it would be better. We can have better communication, and it will resemble the real-life scenario more." (Male student, College of Emergency of Medical Services).

"I personally liked the virtual experience, which I believe is less stressful than the in-person one." (Female student, College of Medicine).

"We wasted sometime in the virtual platform where we waited in the breakout rooms till students in our assigned group joined." (Female student, College of Pharmacy).

\section{Having a COVID-19 Case Was Not Helpful}

The competition case about COVID-19 was not helpful given the novelty of the virus and lack of evidence-based clinical guidelines to manage the case:

"COVID-19 case was slowing our progress as COVID19 is not a well-known disease or disease that we study." (Female student, College of Medicine).

"I would prefer to have a topic that all students have covered before." (Female student, College of Medicine).

"Having a simulated patient and someone to talk to directly would help us to answer the case questions which should not be on COVID-19." (Female student, College of Medicine).

\section{Discussion}

The COVID19 pandemic has impacted all aspects of life, including education. Before the pandemic, there were several attempts to incorporate IPE techniques in different healthcare colleges' courses. However, all of these efforts were paused due to the pandemic. Therefore, the IPEC was designed as a virtual program among healthcare students to revive these efforts. This competition is the first virtual IPE activity for healthcare colleges at the university level, and perhaps in Saudi Arabia to the best of our knowledge.

Expectedly, the IPE competition was perceived favorably by most students, who reported several benefits of this newly introduced learning environment at the university, which is in line with previously published studies. ${ }^{2-6}$ Enhanced communication between students from various healthcare colleges was reported by several students. This is consistent with previously published studies that used a virtual platform among healthcare students and highlighted the vital role the IPE can play in improving the communication between healthcare students who will be the future healthcare providers. ${ }^{14,15}$ In addition, many students have reported a better understanding of the presented case scenario when they worked together with other students from different colleges and felt that their case management strategy was more effective. This has been shown in multiple studies that discussed the educational benefits of the IPE. ${ }^{2-4}$ Furthermore, the students' awareness of their practice scope was improved according to several students. Additionally, the students were able to identify their weaknesses and strengths when they worked alongside peers from other healthcare colleges. These are some advantages of IPE that have been reported in multiple studies. ${ }^{17-19}$ Interestingly, some students stated that the virtual learning environment was less stressful than the inperson environment. Moreover, students had overall favorable views of the virtual learning environment.

However, some students expressed their preference for the in-person learning environment. Also, some have cited different technical issues that delayed the communication between the competing IPE groups. These issues have been discussed and reported in recently published studies on the IPE virtual learning environment during the COVID-19 pandemic. $^{18,19}$ Surprisingly, the students expressed their preference for a non-COVID-19 case and simulated patient. They mentioned several reasons behind their dislike for a COVID-19 case, such as the absence of established clinical guidelines based on evidence for the management of COVID-19. The students suggested having a case with clear evidence-based treatment guidelines, such as diabetes or hypertension. However, the very 
reason the students cited, which is the absence of evidence-based clinical guidelines, was the reason that the organizing committee has chosen this case since it will encourage discussion between students from different colleges. $^{25}$

This study's findings show that virtual learning during the COVID-19 pandemic does not impede the IPE. Moreover, they dispel some myths regarding the academic institutions' ability in the Middle East to adopt and implement IPE in the healthcare education during this unconventional time due to cultural or logistic reasons. However, some limitations of this new experience have to be acknowledged. First, this study's sample size was relatively small, and only two focus group discussions were conducted. Secondly, there was no equal representation of the students from different colleges, given the fact that participation in both the competition and research was voluntary. Furthermore, only $59 \%$ of the students who participated in the IPE competition joined the focus group discussions, which limits the generalizability of the findings. Additionally, despite the fact that IPE competition was chosen to encourage the students to participate and collaborate with each other, it might not be as good as other IPE models in simulating the real practice. Finally, the findings of this study need to be validated using more robust study designs.

\section{Conclusion}

The virtual IPE during the COVID-19 pandemic represented a novel and new learning experience for students. Most of the students valued the virtual IPE experience, and felt that their communication and teamwork skills have improved. In addition, it clarified their roles and the roles of other professions according to multiple students who participated in this activity. Despite some challenges in organizing and running this virtual IPE competition, this study demonstrated that the inclusion of IPE in the undergraduate healthcare curricula is feasible. Future studies should examine the IPE's value from both students' and faculty members' perspectives when it is included in the healthcare colleges' curricula.

\section{Acknowledgment}

The authors also acknowledge financial support from the Researchers Supporting Project number (RSP- 2020/16), King Saud University, Riyadh, Saudi Arabia.

\section{Disclosure}

The authors report no conflicts of interest in this work.

\section{References}

1. Interprofessional Education Collaborative Expert Panel. Core Competencies for Interprofessional Collaborative Practice: Report of an Expert Panel. Interprofessional Education Collaborative Expert Panel; 2011.

2. Carney PA, Thayer EK, Palmer R, Galper AB, Zierler B, Eiff MP. The benefits of interprofessional learning and teamwork in primary care ambulatory training settings. $J$ Interprof Educ Pract. 2019;15:119-126. doi:10.1016/j.xjep.2019.03.011

3. Illingworth $\mathrm{P}$, Chelvanayagam $\mathrm{S}$. The benefits of interprofessional education 10 years on. $B r \quad J$ Nurs. 2017;26(14):813-818. doi:10.12968/bjon.2017.26.14.813

4. Riesen E, Morley M, Clendinneng D, Ogilvie S, Ann Murray M. Improving interprofessional competence in undergraduate students using a novel blended learning approach. J Interprof Care. 2012;26 (4):312-318. doi:10.3109/13561820.2012.660286

5. Nasir J, Goldie J, Little A, Banerjee D, Reeves S. Case-based interprofessional learning for undergraduate healthcare professionals in the clinical setting. $J$ Interprof Care. 2017;31(1):125-128. doi: $10.1080 / 13561820.2016 .1233395$

6. Schmitt MH, Gilbert JH, Brandt BF, Weinstein RS. The coming of age for interprofessional education and practice. Am J Med. 2013;126 (4):284-288. doi:10.1016/j.amjmed.2012.10.015

7. Buring SM, Bhushan A, Broeseker A, et al. Interprofessional education: definitions, student competencies, and guidelines for implementation. Am J Pharm Educ. 2009;73(4):59. doi:10.5688/ aj730459

8. Lutfiyya MN, Brandt B, Delaney C, Pechacek J, Cerra F. Setting a research agenda for interprofessional education and collaborative practice in the context of United States health system reform. $J \quad$ Interprof Care. 2016;30(1):7-14. doi:10.3109/ 13561820.2015.1040875

9. Reimers FM, Schleicher A. A framework to guide an education response to the COVID-19 Pandemic of 2020. OECD. 2020;14 (2020):2020-2024.

10. Tabatabai S. Simulations and virtual learning supporting clinical education during the COVID 19 pandemic. Adv Med Educ Pract. 2020;11:513. doi:10.2147/AMEP.S257750

11. Durfee SM, Goldenson RP, Gill RR, Rincon SP, Flower E, Avery LL. Medical student education roadblock due to COVID-19: virtual radiology core clerkship to the rescue. Acad Radiol. 2020;27 (10):1461-1466. doi:10.1016/j.acra.2020.07.020

12. Hilburg R, Patel N, Ambruso S, Biewald MA, Farouk SS. Medical education during the COVID-19 pandemic: learning from a distance. Adv Chronic Kidney Dis. 2020;27:412-417. doi:10.1053/j. ackd.2020.05.017

13. LeBlanc P. COVID-19 Has Thrust Universities into Online Learning -How Should They Adapt. Brookings (blog); 2020.

14. Prasad N, Fernando S, Willey S, et al. Online interprofessional simulation for undergraduate health professional students during the COVID-19 pandemic. J Interprof Care. 2020;34(5):706-710. doi:10.1080/13561820.2020.1811213

15. Khalili H. Online interprofessional education during and post the COVID-19 pandemic: a commentary. J Interprof Care. 2020;34 (5):687-690. doi:10.1080/13561820.2020.1792424

16. Lackie K, Najjar G, El-Awaisi A, et al. Interprofessional education and collaborative practice research during the COVID-19 pandemic: considerations to advance the field. J Interprof Care. 2020;34 (5):583-586. doi:10.1080/13561820.2020.1807481

17. Jones TA, Vidal G, Taylor C. Interprofessional education during the COVID-19 pandemic: finding the good in a bad situation. $J$ Interprof Care. 2020;34(5):633-646. doi:10.1080/13561820.2020.1801614

18. Wilcha RJ. Effectiveness of virtual medical teaching during the COVID-19 crisis: systematic review. JMIR Med Educ. 2020;6(2): e20963. doi: $10.2196 / 20963$ 
19. Winship JM, Falls K, Gregory M, et al. A case study in rapid adaptation of interprofessional education and remote visits during COVID-19. J Interprof Care. 2020;34(5):702-705. doi:10.1080/ 13561820.2020.1807921

20. Bashatah AS, Al-Ahmary KA, Al Arifi M, et al. Interprofessiona cooperation: an interventional study among saudi healthcare teaching staff at King Saud University. J Multidiscip Healthc. 2020;13:1537. doi:10.2147/JMDH.S279092

21. Al Mohaimeed A, Midhet F, Barrimah I, Saleh MN. Academic accreditation process: experience of a medical college in Saudi Arabia. Int J Health Sci. 2012;6(1):23. doi:10.12816/0005970
22. Hodgkins SR, Marian KM, Shrader S, et al. A case of anaphylaxis: IPE simulation as a tool to enhance communication and collaboration. J Interprof Educ Pract. 2020;18:100303. doi:10.1016/ j.xjep.2019.100303

23. Clarke V, Braun V, Hayfield N. Thematic analysis. Qual Psychol. 2015;222-248.

24. Riis P. Thirty years of bioethics: the Helsinki Declaration 1964-2003. New Rev Bioeth. 2003;1(1):15-25. doi:10.1080/1740028032000131396

25. Centers for Disease Control and Prevention. Interim clinical guidance for management of patients with confirmed 2019 Novel Coronavirus (2019-nCoV) infection. 2020.
Journal of Multidisciplinary Healthcare

\section{Publish your work in this journal}

The Journal of Multidisciplinary Healthcare is an international, peerreviewed open-access journal that aims to represent and publish research in healthcare areas delivered by practitioners of different disciplines. This includes studies and reviews conducted by multidisciplinary teams as well as research which evaluates the results or conduct of such teams or healthcare processes in general. The journal

\section{Dovepress}

covers a very wide range of areas and welcomes submissions from practitioners at all levels, from all over the world. The manuscript management system is completely online and includes a very quick and fair peer-review system. Visit http://www.dovepress.com/testimonials. php to read real quotes from published authors. 